\title{
$\geqslant 0$ \\ (1) \\ CHARACTERISTICS OF LABORATORY PRODUCED HARD GRADE BITUMEN WITH GILSONITE MODIFICATION
}

\author{
P Gopinath ${ }^{1}$, Dr. C. Naveen Kumar ${ }^{2}$, T Nagateja ${ }^{3}$ \\ E-Mail Id: puskurigopinath@gmail.com ${ }^{1}$, naveenkumar_c@ vnrvjiet.in $^{2}$, tnteja@gmail.com ${ }^{3}$ \\ M.Tech Student ${ }^{1}$, Associate Professor ${ }^{2}$, Assistant Professor ${ }^{3}$, Department of Civil Engineering, V.N.R \\ Vignana Jyothi Institute of Engineering and Technology, Hyderabad, Telangana, India
}

\begin{abstract}
Pavements constructed with the conventional bitumen are unable to provide the service throughout the designed life period due to the major distresses like fatigue and rutting. These distresses are mainly due to the factors like exponential increase in repetition of traffic loads and abnormal changes in climatic conditions. To reduce the effect of these distresses the use of High Modulus Asphalt Concrete (HMAC) in the base layer produced with hard grade bitumen can be considered as a solution. In this study, the hard grade bitumen was developed by blending different percentages of Gilsonite (natural asphalt) with conventional VG 30 bitumen. The tests on conventional and gilsonite modified bitumen include physical properties, rotational viscosity test, rolling thin film oven test (RTFO) and SARA fractions. The experimental results show that addition of $15 \%$ of gilsonite (by weight of VG 30) was found to be optimum for the production of hard grade bitumen. The developed hard grade bitumen is satisfying the required specifications as per French method (EME) and can be used to produce HMAC.
\end{abstract}

Keywords-High Modulus Asphalt Concrete (HMAC), Hard Grade Bitumen, Gilsonite Modified Bitumen, Saturates Aromatics Resins Asphaltenes (SARA), Enrobés à module élevé (EME).

\section{INTRODUCTION}

Flexible pavements are the most widely used pavement type across the globe due to lower initial investments and higher riding comfort when compared with rigid pavements. As life of the pavement increases it is being subjected to different types of distress due to increase in traffic volume, vehicular loads and abnormal changes in climatic conditions leading to decrease the life of the pavement and increase the maintenance cost. The performance of bituminous layer of flexible pavement will have major effect on the structural capacity of the pavement as it carries major portion of applied load. Although the drainage parameters of granular layer and strength of subgrade layer may have significant impact on distresses like rutting.

As the traffic intensity and vehicular loads are increasing rapidly the pavements constructed with conventional hot mix asphalt are being subjected to major distresses and decreasing the life of the pavement. To improve the performance of the pavement, Enrobés à module élevé (EME) method which was developed in the year 1980 by France has introduced the concept of using HMAC produced with hard grade binder in the base layer. Hard grade bitumen i.e., those having the penetration value in between $25-15$ at $25^{\circ} \mathrm{C}$. This hard grade bitumen can be produced in the laboratory by modifying base bitumen with hardening additives (natural asphalt) or it can be a refinery product.

The chemical characteristics of a bitumen modified with Gilsonite says that it can be used as a modifier to improve the properties of base bitumen [1]. The addition of Gilsonite has considerably improved the Marshal stability value and the resilient modulus of the HMA mixes [2]. However, the addition of Gilsonite has improved the highperformance temperature of HMA mixes, it shows negative impact on low performance temperature [3].

The rheological properties of the bitumen modified with Gilsonite at high temperatures shows that there is increase in its stiffness, elasticity and rutting resistance significantly [4]. By using HMAC in the bituminous base course, the thickness of the Dense Bituminous Macadam (DBM) layer can be reduced up to $20 \mathrm{~mm}$ which will save the materials and cost substantially [5][6].In other study, using of HMAC prepared with poly phosphoric acid (PPA) modified bitumen, the thickness of DBM layer was reduced up to $40 \mathrm{~mm}$ for $300 \mathrm{msa}$ [7]. The Fourier Transform Infrared Spectroscopy (FTIR) studies were conducted to analyse the evolution of different functional groups when the modified bitumen is subjected to short term and long-term ageing conditions [8].

Another study was conducted to improve the low temperature cracking resistance, compatibility and storage stability by adding polymer to gilsonite modified bitumen [9]. Studies were conducted to improve the fatigue performance of pavement designed with HMAC by adding additives like crumb rubber and FTIR and mechanical interactions between additives and bitumen were studied [10].

The main objective of this study is to produce a hard grade bitumen used for production of HMAC and to study the effects of hardening additive on the properties of the conventional bitumen. American Gilsonite (natural asphalt) was used in the present study as an hardening additive to the conventional bitumen.

\section{MATERIALS AND METHODS}

\subsection{Materials}

\subsubsection{Bitumen}

DOI Number: https://doi.org/10.30780/IJTRS.V04.I11.003

pg. 10

www.ijtrs.com

www.ijtrs.org 
7

In this study, VG 30 bitumen was used as conventional bitumen which was obtained from Tiki Tar industries (Baroda) Limited, Mumbai. The physical properties of conventional bitumen were tested according to the Indian standard specifications (IS 73: 2013). Table 2.1 illustrates the tested results of the conventional bitumen.

Table-2.1 Properties of Conventional Bitumen (VG 30)

\begin{tabular}{|c|c|c|c|c|}
\hline S. No & Properties & Test Method & Result & $\begin{array}{c}\text { Required value } \\
\text { (IS 73:2013) }\end{array}$ \\
\hline $\mathbf{1}$ & Penetration value, $0.1 \mathrm{~mm}$ at $25^{\circ} \mathrm{C}$ & IS 1203 & 51 & 45 (min.) \\
\hline $\mathbf{2}$ & Softening point, ${ }^{\circ} \mathrm{C}$ & IS 1205 & 53 & 47 (min.) \\
\hline $\mathbf{3}$ & Absolute viscosity at $60^{\circ} \mathrm{C}$, Poise & IS 1206 & 3100 & $2400-3600$ \\
\hline $\mathbf{4}$ & Kinematic viscosity at $135^{\circ} \mathrm{C}, \mathrm{cSt}$ & IS 1206 & 370 & $350(\mathrm{~min})$. \\
\hline
\end{tabular}

\subsubsection{Hardening Additive}

American Gilsonite which was obtained from Indian Commercial Company, Mumbai is used as hardening additive in the present study to produce hard grade bitumen. Gilsonite is a natural mineral bitumen, black in colour and brittle in nature, which is easily crushed in to powder. Below Table 2.2 summarizes the properties of Gilsonite powder.

Table-2.2 Properties of American Gilsonite Powder

\begin{tabular}{|c|c|c|c|c|}
\hline S. No & Properties & & Result \\
\hline $\mathbf{1}$ & Penetration value, $0.1 \mathrm{~mm}$ at $25^{\circ} \mathrm{C}$ & & & 0 \\
\hline $\mathbf{2}$ & Softening point, ${ }^{\circ} \mathrm{C}$ & & & 160 \\
\hline $\mathbf{3}$ & Specific Gravity & & & 1.04 \\
\hline $\mathbf{4}$ & Ash content & & & $<1 \%$ \\
\hline $\mathbf{5}$ & Flash point, ${ }^{\circ} \mathrm{C}$ & & 316 \\
\hline $\mathbf{6}$ & Colour in mass & & & Black \\
\hline
\end{tabular}

2.2 Production of hard grade bitumen

The conventional bitumen was heated to a temperature of $150^{\circ} \mathrm{C}$ in a container and the required percentage of additive (by mass of VG 30) was heated to $170^{\circ} \mathrm{C}$ in another container and then mixed with the conventional bitumen. The mixture of additive and the conventional bitumen was blended with higher rate stirrer for 90 mins at a temperature of $160^{\circ} \mathrm{C}$ until homogenous blend was obtained. The process is repeated for $10 \%, 12.5 \%, 15 \%$ and $17.5 \%$ (by mass of VG 30) of Gilsonite. The different percentages of Gilsonite are tried to produce the hard grade bitumen that satisfy the requirement of EME (class 2) method shown in Table 2.3.

Table-2.3 Specifications for Hard Grade Bitumen as per EME Method

\begin{tabular}{|c|c|c|c|}
\hline S. No & Properties & & $\begin{array}{c}\text { Requirement (according to } \\
\text { EME 2) }\end{array}$ \\
\hline $\mathbf{1}$ & Penetration value, $0.1 \mathrm{~mm}$ at $25^{\circ} \mathrm{C}$ & & $15-25$ \\
\hline $\mathbf{2}$ & Softening point, ${ }^{\circ} \mathrm{C}$ & & $55-71$ \\
\hline $\mathbf{3}$ & Kinematic viscosity at $135^{\circ} \mathrm{C}, \mathrm{cSt}$ & & $\geq 600$ \\
\hline $\mathbf{4}$ & $\begin{array}{c}\text { Dynamic (Rotational) viscosity } \\
\text { at } 135^{\circ} \mathrm{C}(\mathrm{Pa} . \mathrm{Sec})\end{array}$ & & 0.6 \\
\hline
\end{tabular}

\subsection{Experimental Tests}

\subsubsection{Physical Tests}

The tests for physical properties like penetration, softening point, ductility and kinematic viscosity were conducted on the conventional bitumen and Gilsonite modified bitumen as per the procedures given in Indian standards. Rotational viscosity test is conducted to determine the mixing and compaction temperature of the conventional bitumen and gilsonite modified bitumen. The mixing and compaction temperatures will be corresponding to dynamic (rotational) viscosities of $170 \mathrm{cSt}$ and $280 \mathrm{cSt}$ will be respectively. Temperatures ranging from 135 to $185^{\circ} \mathrm{C}$ was selected to study the behaviour of samples.

\subsubsection{Rolling Thin Film Oven Test}

The rolling thin oven test (RTFO) is conducted to simulate the short-term ageing during mixing and compaction process. In this test $35 \mathrm{gm}$ of heated bitumen is poured in to the glass bottles and immediately rotated them so that the bitumen will spread throughout the bottle surface. After 90 min of cooling in air, bottles are subjected to a temperature of $163^{\circ} \mathrm{C}$ for $85 \mathrm{~min}$ in the RTFO carousel. 


\subsubsection{SARA Fractions Analysis}

Bitumen is an organic binder which consists of two chemical fractions as asphaltenes and maltenes, which combinedly called as SARA fractions. As maltenes are soluble in n-heptane, asphaltenes and maltenes can be separated from the bitumen. The maltenes can be further separated in to saturates, aromatics and resins by using Liquid Adsorption Chromatography. SARA fractions analysis is conducted as per ASTM D4124 method to determine the asphaltenes content as it effects the rheological properties of bitumen.

In this method $10 \mathrm{gm}$ of bitumen is dissolved in $100 \mathrm{ml}$ per gm of $\mathrm{n}$-heptane and stirred it thoroughly so that the bitumen will not stick to the bottom of glass vessel and is allowed to soak in n-heptane for $24 \mathrm{hrs}$. The asphaltenes which are not soluble in $n$-heptane are separated by using filter paper and suction pump as shown in Fig. 2.1. After drying the filter paper, the difference between the initial and final weights of filter paper is reported as percentage of asphaltenes content in bitumen.

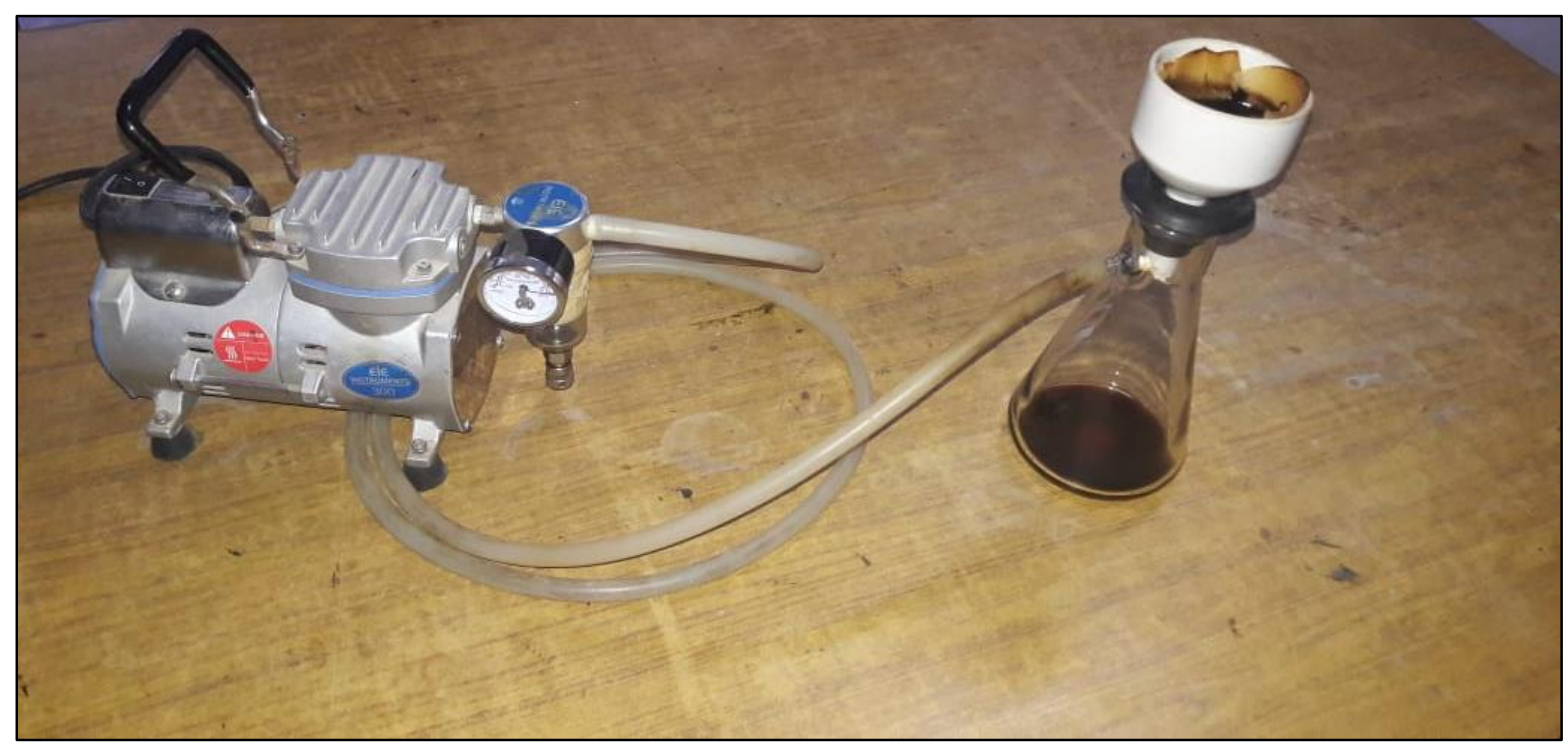

Fig.2.1 Separation of Asphaltenes from Bitumen

\section{RESULTS AND DISCUSSIONS}

\subsection{Effect of Gilsonite on the Physical Properties}

The test results of physical properties of the conventional bitumen and the gilsonite modified bitumen including penetration value and softening point are shown in Fig. 3.1 and 3.2. The test results show that as the percentage of Gilsonite increases the penetration value decreased, while the softening point is increased. This shows that the performance of the gilsonite modified bitumen has improved at high temperatures. The penetration values of conventional bitumen and gilsonite modified bitumen $(10 \%, 12.5 \%, 15 \%$ and $17.5 \%$ by weight of VG 30$)$ are 51 , $37,28,22$ and 18 respectively. The softening point of $15 \%$ of gilsonite modified bitumen was increased by $11^{\circ} \mathrm{c}$ when compared with conventional bitumen. Literature says that the acceptable ductility value of hard grade bitumen is $10 \mathrm{~cm}$ at $25^{\circ} \mathrm{C}$ [11]. Table 3.1 shows the test results of conventional bitumen and gilsonite modified bitumen.

The optimum percentage is selected as $15 \%$ of gilsonite by weight of conventional bitumen to produce hard grade bitumen as the penetration value is between 25-15. Table 3.2 shows the test results of hard grade bitumen produced in this study with EME2 specifications.

Table-3.1 Test Results of Conventional Bitumen and Gilsonite Modified Bitumen.

\begin{tabular}{|c|c|c|c|}
\hline & Penetration value & Softening point $\left.\mathbf{~}^{\mathbf{}} \mathbf{C}\right)$ & $\begin{array}{c}\text { Kinematic Viscosity } \\
\text { (cSt) }\end{array}$ \\
\hline VG 30 & 51 & 53 & 380 \\
\hline VG 30+10\% Gilsonite & 37 & 57 & 780 \\
\hline VG 30+12.5\% Gilsonite & 28 & 61 & 1100 \\
\hline VG 30+15\% Gilsonite & 22 & 64 & 1530 \\
\hline VG 30+17.5\% Gilsonite & 18 & 67 & 2240 \\
\hline
\end{tabular}

DOI Number: https://doi.org/10.30780/IJTRS.V04.I11.003

pg. 12

WWW.ijtrs.com

www.ijtrs.org 


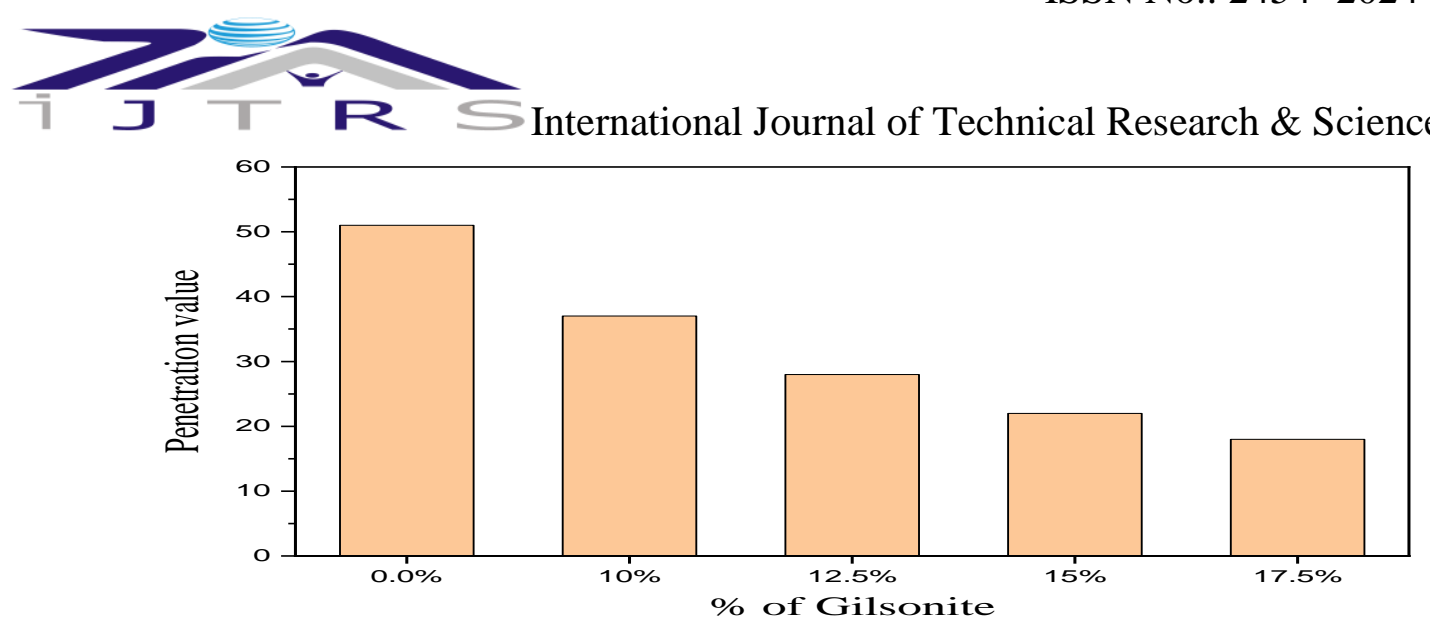

Fig.3.1 Penetration Values of Conventional Bitumen and Gilsonite Modified Bitumen

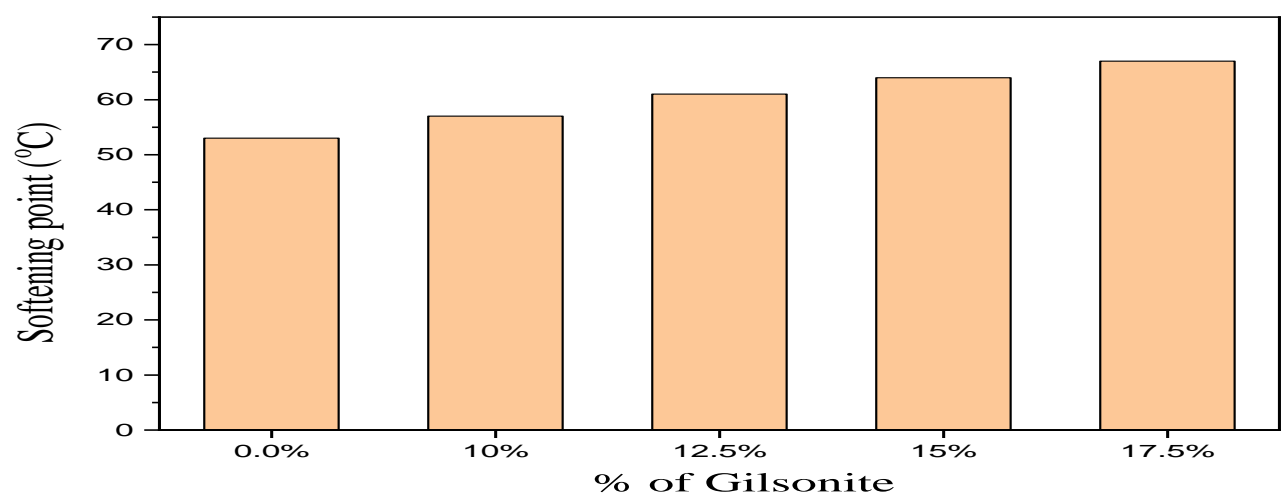

Fig.3.2 Softening Point of Conventional Bitumen and Gilsonite Modified Bitumen

Table-3.2 Test Results of Hard Grade Bitumen Produced with EME2 Specifications.

\begin{tabular}{|c|c|c|c|c|}
\hline S. No & Properties & Test Method & Result & $\begin{array}{c}\text { Requirement (according } \\
\text { to EME2) }\end{array}$ \\
\hline $\mathbf{1}$ & Penetration value, $0.1 \mathrm{~mm}$ at $25^{\circ} \mathrm{C}$ & IS 1203 & 22 & $15-25$ \\
\hline $\mathbf{2}$ & Softening point, ${ }^{\circ} \mathrm{C}$ & IS 1205 & 64 & $55-71$ \\
\hline $\mathbf{3}$ & Kinematic viscosity at $135^{\circ} \mathrm{C}, \mathrm{cSt}$ & IS 1206 & 1550 & $\geq 600$ \\
\hline $\mathbf{4}$ & Ductility at $25^{\circ} \mathrm{C}, \mathrm{cm}$ & IS 1208 & 21 & 0.6 (Min.) \\
\hline $\mathbf{5}$ & $\begin{array}{c}\text { Dynamic (Rotational) viscosity } \\
\text { at } 135^{\circ} \mathrm{C}(\mathrm{Pa} . \mathrm{Sec})\end{array}$ & & 1.53 & \\
\hline
\end{tabular}

\subsection{Rotational Viscosity Test Results}

The viscosity of the modified bitumen is dependent on temperature. As the temperature increases, viscosity decreases. The results of dynamic (rotational) viscosity of conventional bitumen and gilsonite modified bitumen at $135^{\circ} \mathrm{C}$ are shown in Fig 3.3. The handling of bitumen will be easy at the lower viscosity values for mixing and compaction. The mixing temperature corresponding to $170 \mathrm{cSt}$ and compaction temperature corresponding to 280 cSt was increased by $20^{\circ} \mathrm{C}$ for $15 \%$ of gilsonite. As the addition of additive is increasing the viscosity of bitumen, it increases the cohesion between the bitumen and aggregate in bituminous mix. The mixing and compaction temperatures of conventional and gilsonite modified bitumen are shown in Fig 3.4.

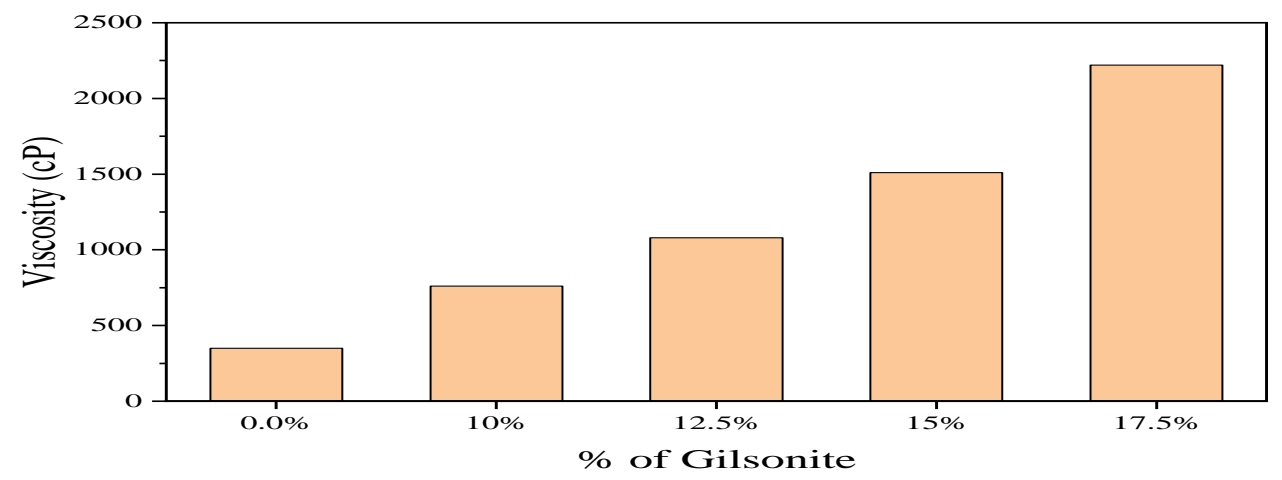

Fig.3.3 Viscosity of Conventional Bitumen and Gilsonite Modified Bitumen DOI Number: https://doi.org/10.30780/IJTRS.V04.I11.003

WWw.ijtrs.com

WWw.ijtrs.org 

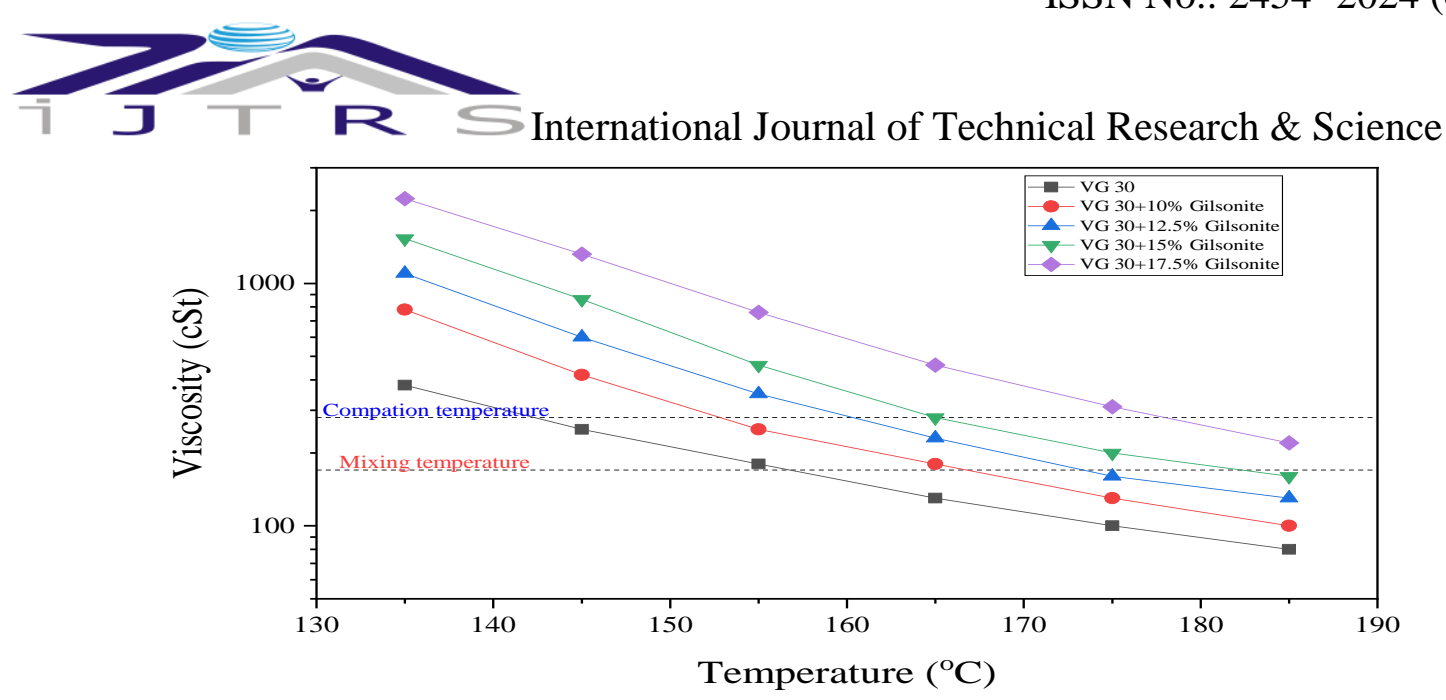

Fig.3.4 Mixing and Compaction Temperatures of Conventional Bitumen and Gilsonite Modified Bitumen 3.3 SARA Fractions Analysis Results

SARA fractions analysis was conducted on both the conventional bitumen and modified bitumen. The analysis says that the asphaltenes percentage increases as the percentage of gilsonite increases. The asphaltenes percentages for the conventional bitumen and gilsonite modified bitumen before and after short term ageing are shown in Fig 3.5. Asphaltenes percentage for conventional bitumen and $15 \%$ of gilsonite modified bitumen before ageing was $16 \%$ and $31 \%$ and was increased to $20 \%$ and $34 \%$ after short term ageing respectively.

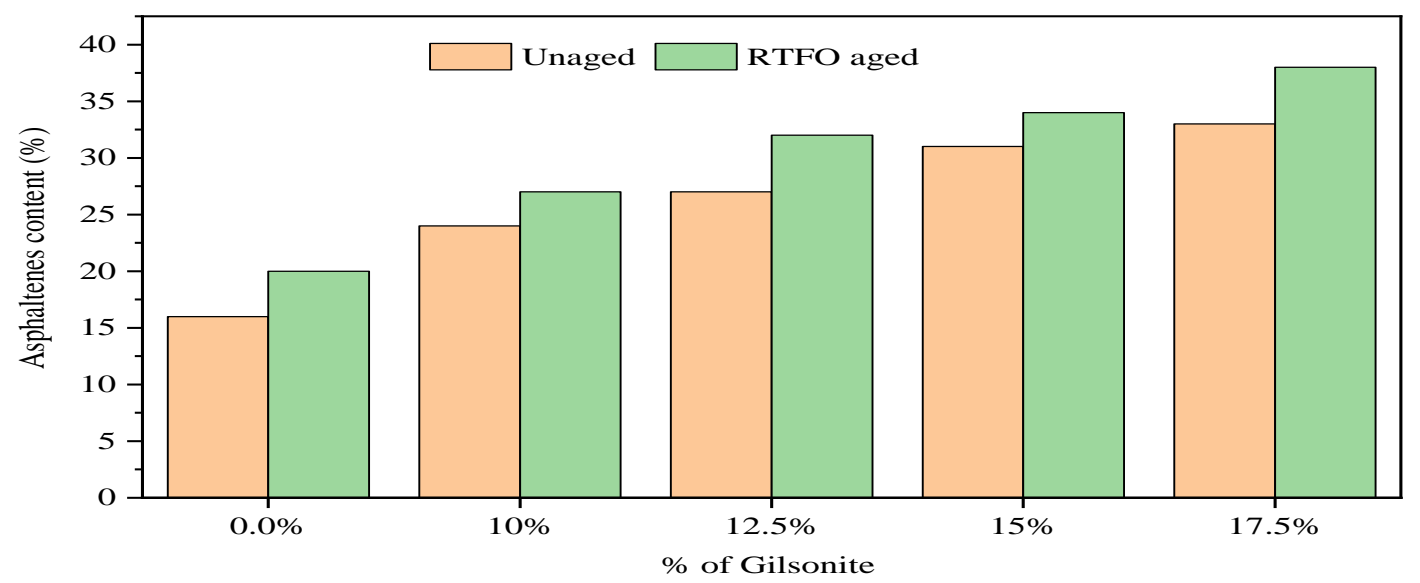

Fig. 3.5 Asphaltenes Content (\%) for Aged and Unaged Bitumen

\section{CONCLUSIONS}

The current study is carried out to develop hard grade bitumen by adding gilsonite to conventional bitumen VG 30. The developed hard grade bitumen will be used in design of HMAC according to French EME method. The conclusions drawn from the study are

$>$ Optimum percentage to produce hard grade bitumen was selected as $15 \%$ of Gilsonite (by weight of conventional bitumen).

$>$ 2.The developed hard grade bitumen is satisfying the required specifications as per French method (EME) and can be used to produce HMAC.

$>$ 3.As the penetration value of hard grade bitumen is decreased by $57 \%$ of conventional bitumen, its resistance to penetration is more than conventional bitumen.

$>$ 4.The temperature susceptibility of hard grade GMB bitumen has been reduced due to increase in softening point by $11^{\circ} \mathrm{C}$ when compared with conventional bitumen.

$>$ 5.The mixing and compaction temperatures of hard grade bitumen are increased by $25^{\circ} \mathrm{C}$ when compared to conventional bitumen.

$>$ 6.Asphaltene content increased from $16 \%$ to $20 \%$ and $24 \%$ to $27 \%$ for conventional and modified respectively after subjecting to short term ageing.

\section{REFERENCES}

[1] Nader Nciri, Suil Song, Namho Kim, Namjun Cho, "Chemical Characterization of Gilsonite Bitumen", Petroleum \& Environmental Biotechnology, 2014.

[2] H.R. Jahaniah, Gh. Shafabaksha, H. Divandari," Performance evaluation of Hot Mix Asphalt (HMA) containing bitumen modified with Gilsonite", Construction and Building Materials, Vol. 131, pp. 156-164, 2017. 
ᄀ $\mathrm{I} \cong$ International Journal of Technical Research \& Science

[3] Mahmoud Ameri, Ahmad Mansourian, Saeid Salehi Ashani, Golazin Yadollahi, "Technical Study on the Iranian Gilsonite as an additive for modification of asphalt binders used in pavement construction", Construction and Building Materials, Vol. 25(3), pp. 1379-1387, 2010.

[4] Aliasghar Akbar Nasrekani, Koorosh Naderi, Mostafa Nakhaei, "High-temperature performance of gilsonitemodified asphalt binder and asphalt concrete", Petroleum Science and Technology, Vol. 34(21), pp. 17831789, 2016.

[5] Abhishek Mittal, Khusboo Arora, Gajendra Kumar and Pramood Kumar Jain, "Comparative studies on Performance of Bituminous Mixes Containing Laboratory Developed Hard Grade Bitumen”, Advances in Civil Engineering Materials (ASTM), 2018.

[6] Siksah Swaroopa Kar, Khusboo Arora, Chdrakanth Mani and Dr. P K Jain, "Characterization of Bituminous Containing Hard Grade Bitumen”, Transportation Research Procedia, Vol. 17, pp. 349-358, 2016.

[7] G Sandeep Reddy, Penki Ramu, "Design of Bituminous Mixes for Heavily Trafficked Roads-A Boon to Indian Roads", International Journal of Technical Research \& Science, Vol. 6(4), pp. 34-38, 2019.

[8] M.R. Nivitha, Edamana Prasad and J.M. Krishnan, "Ageing in modified bitumen using FTIR spectroscopy", International Journal of Pavement Engineering, Vol. 17(7), 2016.

[9] Shisong Ren, Ming Liang, Weiyu Fan, Yuzhen Zhang, Chengduo Qian, Ying He, Jingtao Shi, "Investigating the effects of SBR on the properties of gilsonite modified asphalt", Vol. 190, pp. 1103-1116, 2018.

[10] Basim H. Al-Humeidawi, Mutaz Kadhim Medhlom, Kassim Kadhim Hameed, Huda A. Kadhim, "Production of Hard Grade Bitumen for Using in High Modulus Asphalt Concrete”, Journal of University of Babylon for Engineering Sciences, Vol. 26(6), 2018.

[11] Espersson, M., "Effect in the high modulus asphalt concrete with the temperature", Construction and Building Materials, pp. 638-643, 2014.

[12] IRC:37-2012, Guidelines for the Design of Flexible pavements, Indian roads Congress, New Delhi, India, www.irc.nic.in, 2012.

[13] IS:73-2013, Paving Bitumen-Specifications, Bureau of Indian Standards, New Delhi, India, www.bis.gov.in, 2013.

[14] MORTH, Specifications for Road and Bridge Works, Ministry of Road Transport and Highways, New Delhi, India, www.india.gov.in, 2013. 